Military Technical College

Kobry El-Kobbah,

Cairo, Egypt

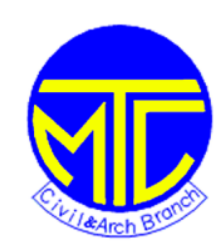

$8^{\text {th }}$ International Conference on

Civil and Architecture

Engineering

ICCAE-8-2010

\title{
Numerical Simulation of the Effect of Geotechnical Conditions on Wave Propagation of Underground Explosion in Rock Mass
}

\author{
Hazem A. Hasan*, Ismail M. Kamal **
}

\section{Abstract:}

The damage prediction of rock mass under blast loads induced by explosions is essential in rock engineering. Due to the expensive costs of field test measurements, numerical simulation is considered one of the most efficient procedures to predict the response of rock mass under the effect of underground explosion. In this paper finite element technique is used to simulate the dynamic behavior and failure conditions of rock mass subjected to the explosion load. The validation of the finite element model was based on a field experiment conducted in the mountainous regions between BeniSwef and Elminia, Egypt, [1].

Numerical simulation considered the mechanical properties of rock mass based on the inherent mechanical properties relative to intact rock. Nonlinear three-dimensional numerical simulation of this experimental investigation was carried out using AUTODYN, which is probably the most extensive written code dealing with explosion problems. A comparison between the results determined by the numerical simulation and the field measurements was performed. The simulation results showed a good compatibility with the field measurements.

Keywords: wave propagation, explosion, 3D-Simulation, AUTODYN-3D

\section{Introduction}

Understanding the response of rock mass due to explosion load is essential in order to assign the safety of fortified structures such as; rock tunnels and shelters to resist the dynamic load induced by conventional weapons attacks.

*Ph.D., Candidate, Civil Eng. Department, Military Technical College, Egypt.

Assoc. Prof., Civil Eng. Department, Military Technical College, Egypt. 
A blast wave is thus fast moving compressed air and acting on the surrounding rock by an effectively instantaneous rise in pressure followed by a decay of wave propagation in the rock masses [2].

In an underground explosion, the rock masses surrounding the underground structures may produce four zones along the distance from the detonation source. First, a crushed zone is formed near the wall of the rock chamber where the stable shock wave is induced and the rock mass is totally crushed. This is followed by a fractured zone where the unstable shock wave occurs and new fractures are produced. Then, the blast wave goes through a plastic zone and an elastic zone where the blast wave is changed to plastic wave and elastic wave, respectively. Finally the blast wave will be attenuated completely because of the geometric damping and material damping [3]. Study of the blast induced stress wave propagation with numerical methods has been quite extensive over the last two decades [4]. In most of these studies, isotropic continuum damage models were adopted. Recently, an anisotropic damage model with an equivalent material approach has been developed by the authors to analyze the stress wave propagation in a rock mass [5].

Previous research work showed that continuum damage models are effective numerical methods to simulate the elastic degradation caused by pre-existing microcracks in rock mass. Although rock always exhibits anisotropy after macrocracks occur, once isotropic damage model is proved as an effective method to estimate the gross damage of rock mass subjected to blast. The damage of rock mass under shock loading was observed by the stress strain tests both on shock-damaged gabbro and limestone. It was found that the effective Young,s modulus decreases with increasing initial damage parameter value, and an apparent work-softening process occurs before failure. Thus, properly considering rock damage characteristics in numerical simulation of wave propagation is very important since the dissipation of energy by damage and plastic flow will cause rapid attenuation of shock wave [6]. This paper employs the explicit dynamic finite element code 3D-AUTODYN to analyze the behavior of rock mass due to explosion.

\section{Description of the field test problem}

The selected problem to be investigated is a field-blasting carried out at the limestone site by H. A. Hasan et al. [1]. The field layout is shown in Figure (1), consists of cylindrical TNT charge which was used to perform the test procedure. A vertical charge holes of about $3 \mathrm{~m}$ in depth and $0.1 \mathrm{~m}$ in diameter was drilled and the explosive charges $(\mathrm{W}=8 \mathrm{Kg}$ TNT) were placed inside the hole at depth of $0.5 \mathrm{~m}$ under the ground surface. The targets locations were at constant horizontal distance of values $5 \mathrm{~m}$ from the charge center, directly under the ground surface for targets $\mathrm{G}_{1}$ and at depth of $1 \mathrm{~m}$ below the ground surface for target $\mathrm{G}_{2}$. 


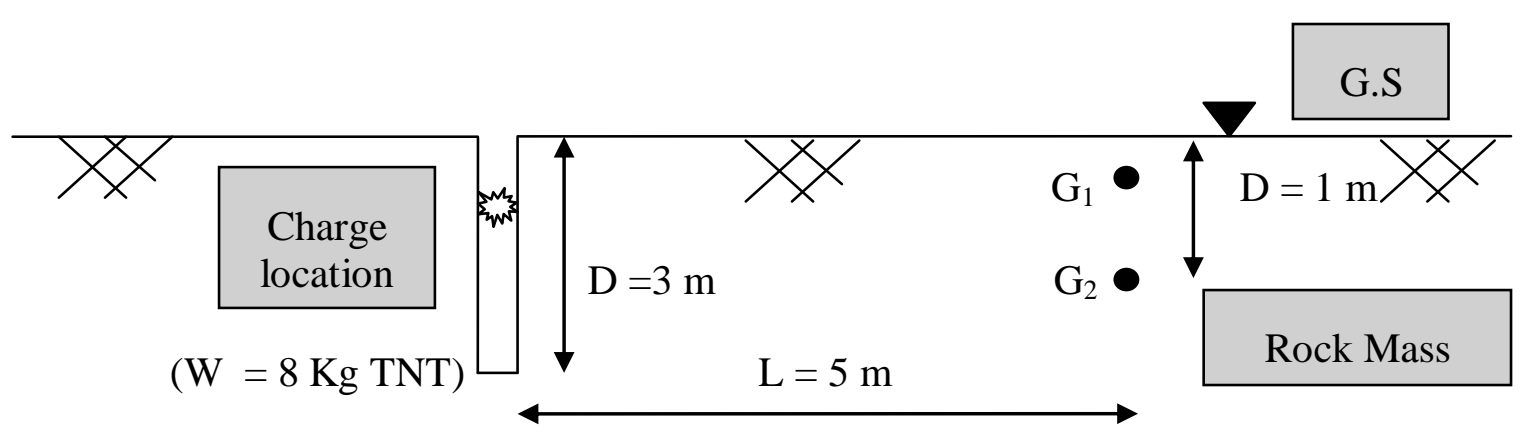

Figure: (1) Layout of explosion tests

\section{Finite Element Model}

Nonlinear three-dimensional numerical finite element model was carried out using AUTODYN code to simulate the dynamic response of the selected field test problem. The set of experimental data conducted by H. A. Hasan, et al.,[1] were used to accomplish the simulated problem. Also, stress wave propagation in the rock mass generated from underground explosion was simulated.

\subsection{Numerical model}

Three dimensions finite element model used in this study is shown in Figure (2). The simulated rock mass with dimensions of $25 \times 5 \times 5 \mathrm{~m}$ in $\mathrm{X}, \mathrm{Y}, \mathrm{Z}$ directions respectively. Two target points are located directly under the ground surface $\left(\mathrm{G}_{1}\right)$ and at depth of $1 \mathrm{~m}$ from the ground surface $\left(\mathrm{G}_{2}\right)$ with horizontal target - charge distances of $5 \mathrm{~m}$ from the explosion location as shown in Figure (3). The mesh with $12.5 \mathrm{~cm} \mathrm{x}$ $10 \mathrm{~cm} \times 10 \mathrm{~cm}$ in $\mathrm{X}, \mathrm{Y}, \mathrm{Z}$ directions respectively was used to represent the numerical model, zoning technique in $X$ - direction was used to make the mesh finer to be $10 \mathrm{~cm}$ $\mathrm{x} 10 \mathrm{~cm} \times 10 \mathrm{~cm}$ in the region between the explosion and target location as shown in Figure (3).

As shown in Figure (4), the effective TNT charge is $8 \mathrm{Kg}$ TNT, located at depth of $0.5 \mathrm{~m}$ under the ground surface.

The problem to be studied with AUTODYN can be characterized as highly time dependent with both geometric and material non-linearities. Different numerical tools were used in some previous studies in order to solve similar problems of explosion. For examples, G.W. et al., [6] and C.Wu et al., [6], [7],[8]. The software AUTODYN v6.1 [9] is a hydrocode that uses finite-difference, finite volume, and finite element techniques to solve a wide variety of non-linear problems in solid, fluid and gas dynamics. The hydrocode uses the differential equations governing unsteady material dynamic motion such as; the local conservation of mass, momentum and energy. In order to obtain a complete solution, in addition to appropriate initial and boundary conditions, it is necessary to define a further relation between the flow variables. This can be found in a material model, which relates stress to deformation and internal 
energy (or temperature). In most cases, the stress tensor may be separated into a uniform hydrostatic pressure (all three normal stresses equal) and a stress deviatoric tensor associated with the resistance of the material to shear distortion. The relation between the hydrostatic pressure, the local density (or specific volume) and local specific energy (or temperature) is known as an equation of state. Since solids are able to withstand a certain amount of tensile stress, it is necessary to consider extending the equations of state into limited regions of negative values of the pressure (tension). The hydrodynamic tensile limit, sometimes referred to as $\mathrm{p}_{\min }$, is the minimum pressure at which the material can sustain continuous expansion. If the material pressure drops below this limit in a cell it is assumed that the material will fracture, or in some way lose its uniform and continuous ability to sustain a tensile pressure.

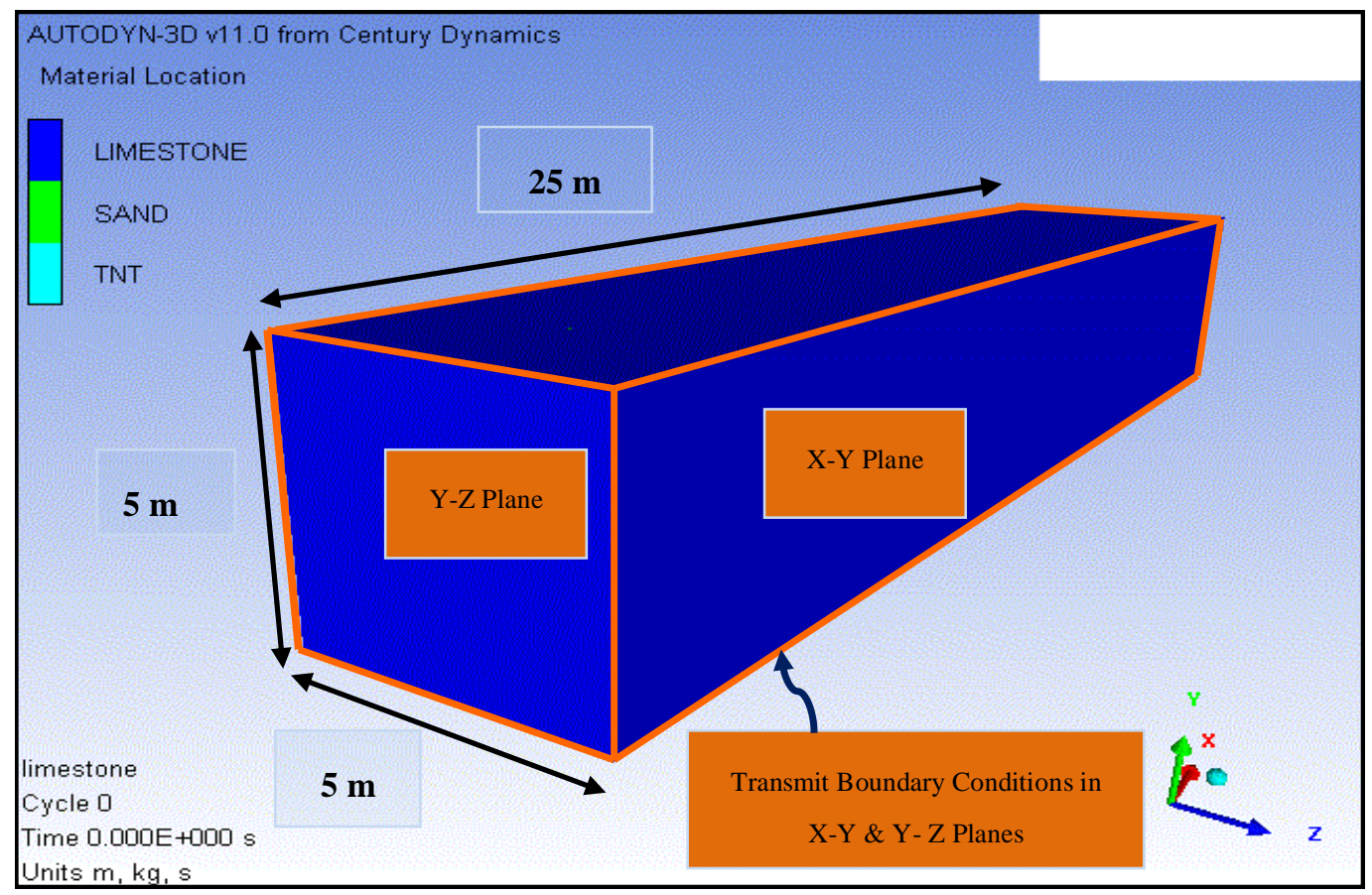

Figure (2): Geometry of the numerical model

\subsection{Material Modeling}

The governing equations are the conservation of mass, momentum and energy. To complete the description of the continuum, additional relations describing the material behavior is needed (besides the load and boundary conditions): it is the material model which typically four basic types of information must be specified for each material:-

1. Equation of State: Pressure as function of density and internal energy. 
2. Strength model: Strength model, which defines the yield surface.

3. Failure model: Failure model prescribing when the material no longer has strength.

4. Erosion model: Erosion criteria. When a material is eroded it is transformed from solid element to a free mass node (Lagrange only).

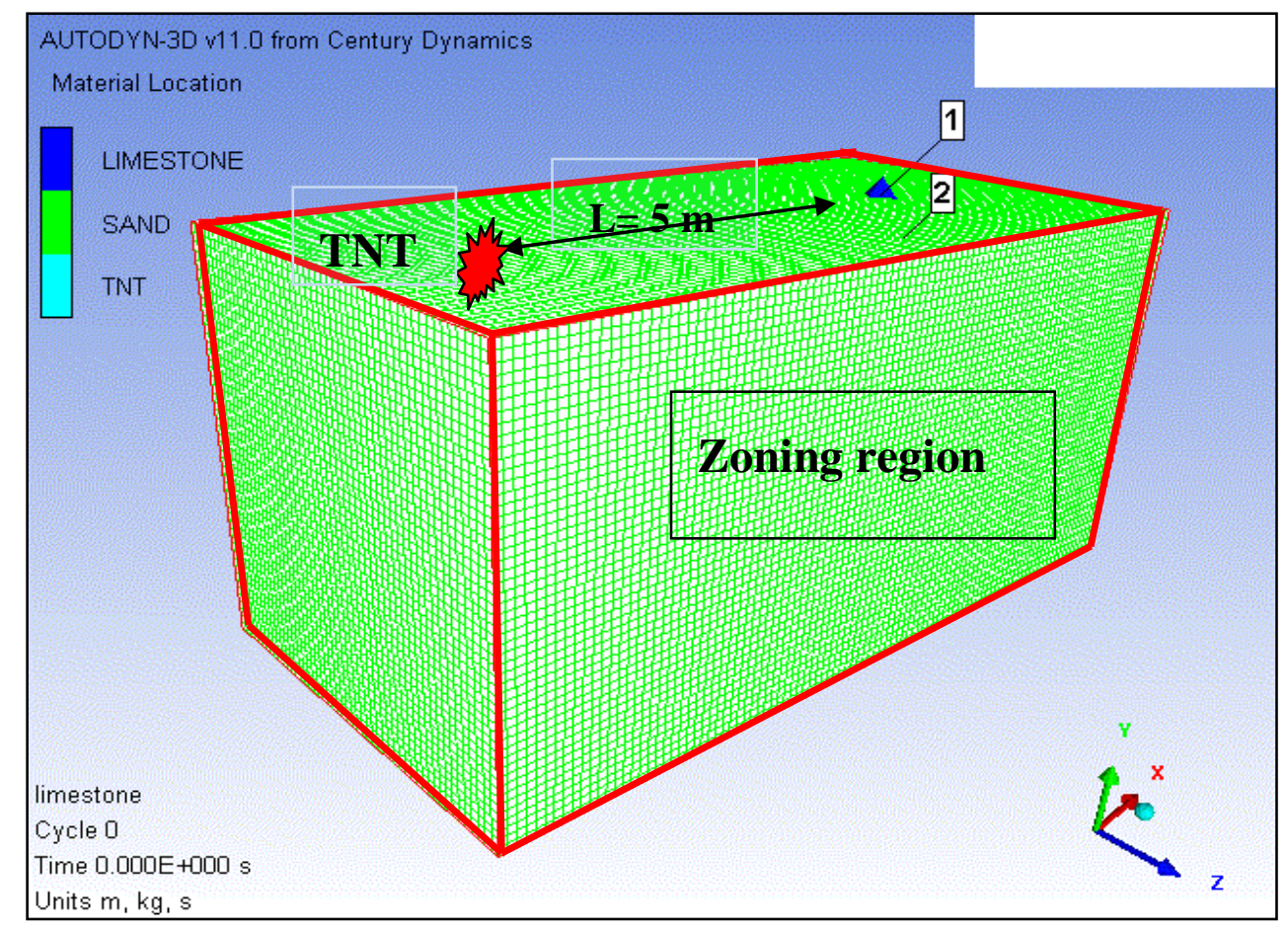

Figure (3): Zoning effect between Charge - Targets horizontal distance

\subsubsection{TNT}

The numerical modeling of the TNT charge is simulated by Lagrange processor mesh and satisfies the equation of state (EOS) of Jones - Wilkins - Lee (JWL), standard constant of TNT is from AUTODYN library [9]. TNT material will be automatically converted to ideal gas equation of state after it changes to gas with high energy.

\subsubsection{Sand}

The sand was used to fill the hole which was drilled in the rock mass after the TNT charge was located inside the hole. The sand was numerically modeled to satisfy the compaction equation of state with MO granular failure model which is defined in AUTODYN library. 


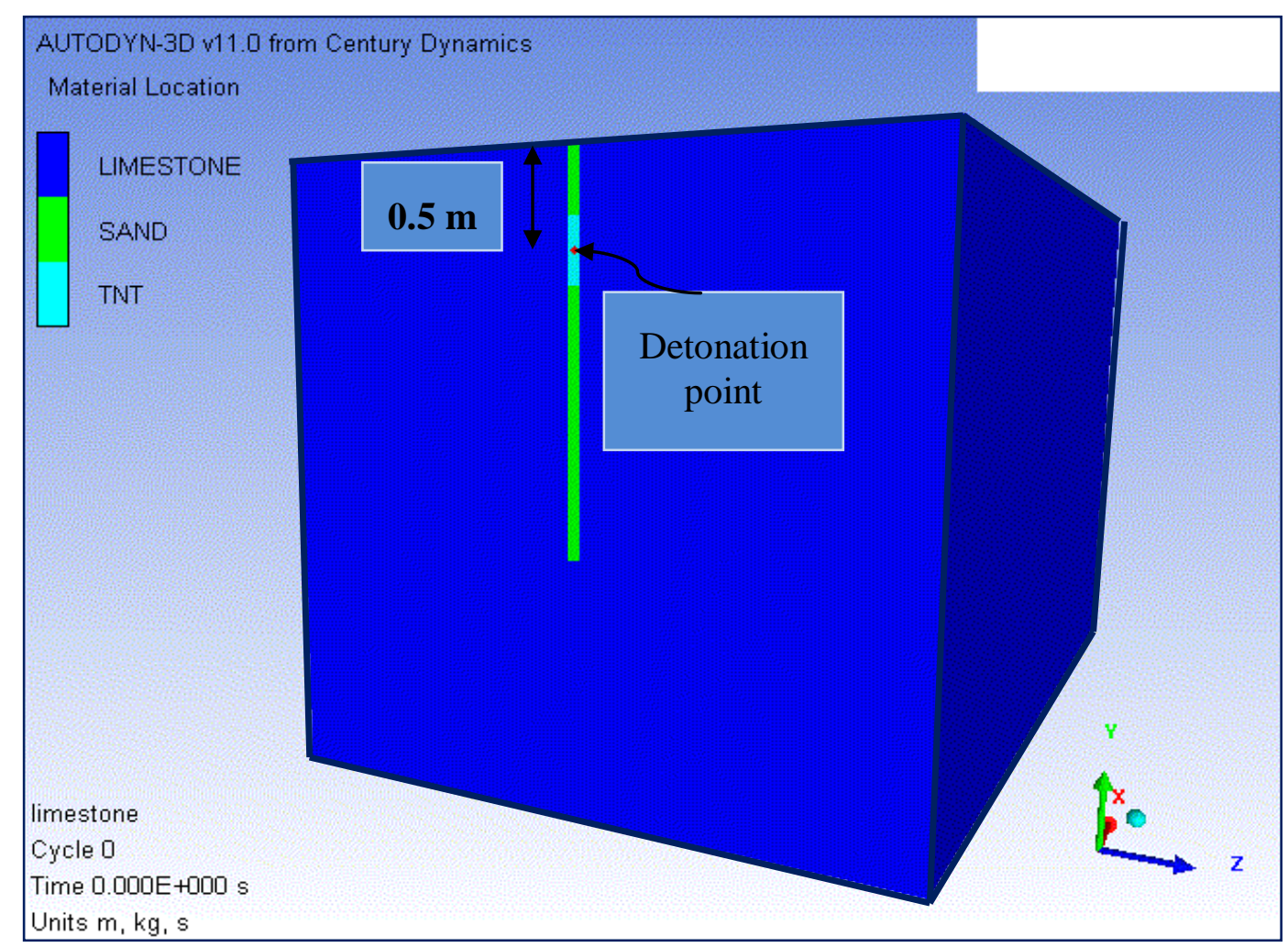

Figure (4): Vertical location of TNT charge

\subsubsection{ROCK}

Rock is simulated by 500000 elements of Lagrange processor mesh and satisfies the linear equation of state. Transmitting boundary condition is used to reduce the reflection of stress wave from the numerical boundaries. The material properties of the simulated rock mass were obtained according to the Hoek-Brown failure criterion. The parameters defining the Hoek-Brown criterion can be estimated from a combination of laboratory tests on intact rock and an empirical adjustment to account for the reduced strength of the rock mass due to the presence of weakness and joints[10]. Table (1) presents the empirical equations which transform the mechanical properties of intact rock obtained from unconfined compressive strength tests to the equivalent rock mass which were used in the numerical simulation as shown in Table (2) [11], [12]. According to [13] and many other studies, RHT material model is used for rock material modeling. It is a modular strength model for brittle materials developed by Riedel, [14] is particularly useful for modeling the dynamic loading of rock, that is because the model computes the following phenomena associated with brittle materials; (Pressure hardening; Strain hardening; Strain rate hardening; Third invariant dependence for compressive and tensile meridians; Damage effects; Strain softening and Crack-Softening). 
where:

$\mathrm{mi}, \mathrm{mb}$ : dimensionless parameters for intact rock and rock mass respectively, the values of which depend on the tested rock type.

$\mathrm{s}, \mathrm{a}$ : dimensionless parameters depend on the value of GSI.

GSI : Geological Strength Index, the value of which depends on the characteristics of rock mass.

D : factor depends on the degree of disturbance to which the rock mass has been subjected by blast damage and stress relaxation.

бci : unconfined compressive strength of intact rock.

$\sigma_{\mathrm{c}}$ : unconfined compressive strength of rock mass.

$\mathrm{E}_{\mathrm{i}}$ : Young's modulus of intact rock.

$\mathrm{E}_{\mathrm{rm}}$ : Young's modulus of rock mass.

Table (1) Hoek-Brown failure criterion to equivalent rock mass [11]

\begin{tabular}{|c|c|}
\hline Equation & Variables \\
\hline$m_{b}=m_{i} \exp ((G S I-100) / 28-14 D)$ & $\begin{array}{l}\mathrm{m}_{\mathrm{i}}=8, \mathrm{GSI}=30, \\
\mathrm{D}=0.8, \mathrm{~m}_{\mathrm{b}}=0.124\end{array}$ \\
\hline $\mathrm{s}=\exp ((\mathrm{GSI}-100) / 9-3 \mathrm{D})$ & $\mathrm{s}=3.38 \mathrm{E}-4$ \\
\hline $\mathrm{a}=1 / 2+1 / 6\left(\mathrm{e}^{-\mathrm{GSI} / 15}-\mathrm{e}^{-20 / 3}\right)$ & $a=0.522$ \\
\hline$\sigma_{\mathrm{c}}=\sigma_{\mathrm{ci}} \mathrm{s}^{\mathrm{a}}$ & \begin{tabular}{|l}
$\sigma_{\mathrm{ci}}=25 \mathrm{MPa}$ \\
$\mathrm{s}^{\mathrm{a}}=0.0154$, \\
$\sigma_{\mathrm{c}}=0.38 \mathrm{MPa}$
\end{tabular} \\
\hline $\mathrm{E}_{\mathrm{rm}}=\mathrm{E}_{\mathrm{i}}\left[0.02+\left((1-\mathrm{D} / 2) /\left(1+\mathrm{e}^{((60+15 \mathrm{D})-\mathrm{GSI}) / 11}\right)\right)\right]$ & $\begin{array}{l}\mathrm{E}_{\mathrm{i}}=250 \mathrm{MPa}, \\
\mathrm{E}_{\mathrm{rm}}=8.22 \mathrm{MPa}\end{array}$ \\
\hline
\end{tabular}


Table (2) Mechanical properties of intact rock and equivalent rock mass

\begin{tabular}{|c|c||c|}
\hline \hline Mechanical properties & Intact rock & Rock mass \\
\hline Young's modulus (MPa) & 250 & 8.22 \\
\hline Uniaxial compressive strength $(\mathrm{MPa})$ & 25 & 0.38 \\
\hline Unit weight $\left(\mathrm{kN} / \mathrm{m}^{3}\right)$ & 26.5 & 26.5 \\
\hline Poisson's ratio & 0.3 & 0.3 \\
\hline Bulk modulus (MPa) & 208.33 & 6.85 \\
\hline Shear modulus (MPa) & 96.2 & 3.16 \\
\hline
\end{tabular}

\subsection{Model Interaction}

Rock-TNT interaction was achieved using the gap interaction logic. In the gap interaction logic, each surface segment is surrounded by a contact detection zone. The radius of this contact detection zone is called the gap size. Any node entering the contact detection zone of a surface segment are repelled by a force proportional to the crater diameter of the node into the contact detection zone.

\section{$\underline{3.4 \text { Erosion algorithm }}$}

It can be used to solve the excessive element distortion problem and model the fracture and failure of rock mass due to explosion load. The element immediately deleted when the material response in an element reaches a certain value according to the modeled material. This value depends on two erosion criteria (tensile cut-off and shear strain) which correspond to material tensile fracture and compression-shear failure) respectively. The deletion process is irreversible which means that when the applied load is reversed, the deleted material will not be able to offer further resistance. This technique can be employed to capture the physical fracture and failure process [15]. 


\section{Results and discussion}

\subsection{Crater formation}

For the finite element proposed model, the dynamic response of the rock mass is determined in terms of crater formation which caused damage to rock mass. Figure (5) shows the field test and numerical results of crater formation. It is clear that the predicted crater by using the erosion algorithm is formed by two parts: the upper part between the borehole collar and the ground surface, formed by the reflected stress wave [16], and the lower part near the explosive collar, formed by the high shear stress and tangential tensile stress surrounding the borehole. The average field test crater dimensions measured as 2.55 in diameter $\mathrm{m}$ and $2.7 \mathrm{~m}$ in depth agrees with the numerical model crater dimensions of $3 \mathrm{~m}$ in diameter and $2.5 \mathrm{~m}$ in depth which is calculated by the proposed model. The difference between results of field test and proposed model were $7 \%$ for crater and $15 \%$ for depth. This difference is very small for this type of studies considering the uncertainties involved. The crater dimensions results of the experimental and numerical analysis are listed in Table (3).
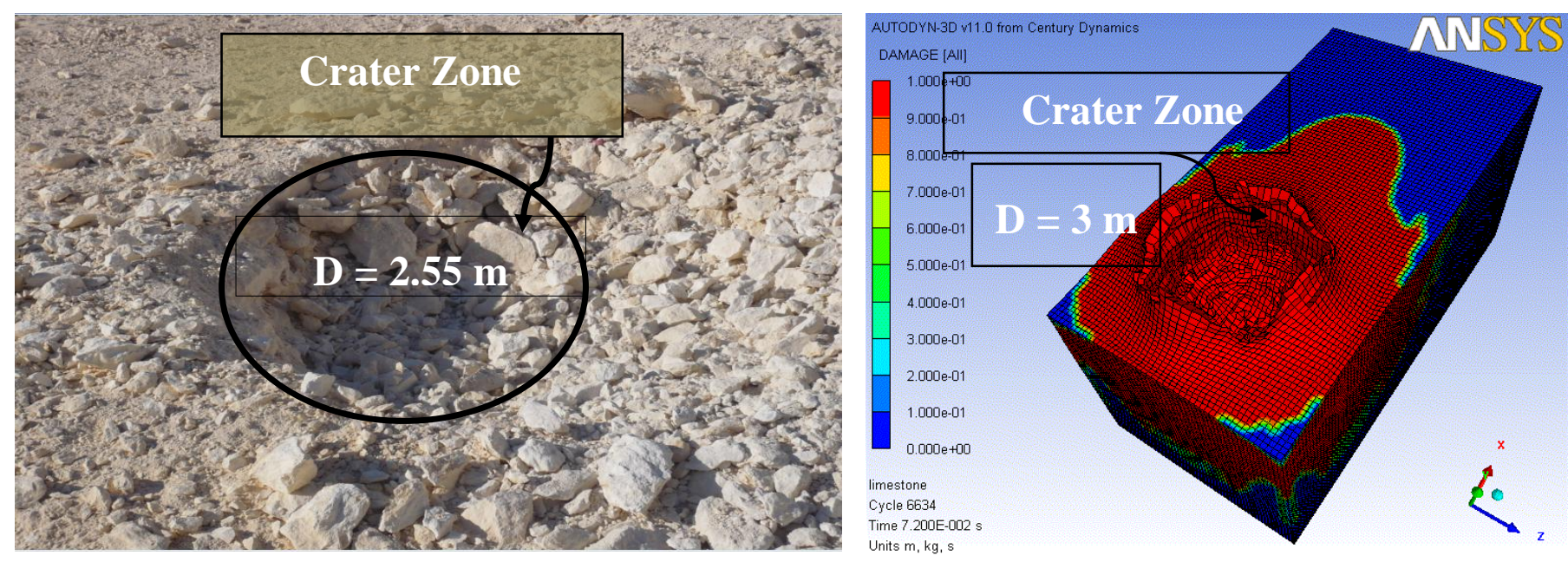

Figure (5): Field test and numerical model results of Crater formation

\subsection{Incident pressure}

The calculated pressure-time history for the two targets location $\left(\mathrm{G}_{1}\right)$, directly under the ground surface, and $\left(\mathrm{G}_{2}\right)$, at depth $(\mathrm{D}=1 \mathrm{~m})$ under the ground surface, are shown in Figures (6) and (7). In Figure (6), the incident pressure on target $\left(\mathrm{G}_{1}\right)$ is compression due to the initial shock front wave on the rock mass and the peak pressure is approximately $\left(\mathrm{P}_{\max }=98 \mathrm{kPa}\right)$. The stress subsequently becomes tensile in nature with value of $(\mathrm{P}=20 \mathrm{kPa})$ and changes into compression again, while the maximum pressure value of the experimental test results is $\left(\mathrm{P}_{\max }=140 \mathrm{kPa}\right)$. In Figure (7), it is easy to notice that the target $\left(G_{2}\right)$ mainly experiences high 
compressive stress up to $\left(\mathrm{P}_{\max }=142 \mathrm{kPa}\right)$ and tensile stress $(\mathrm{P}=56 \mathrm{kPa})$, while the maximum pressure value of the experimental test results is $\left(\mathrm{P}_{\max }=168 \mathrm{kPa}\right)$. The maximum incident pressure on target $\left(\mathrm{G}_{2}\right)$ is greater than its value on target $\left(\mathrm{G}_{1}\right)$ due to the deeper location of target $\left(G_{2}\right)$ than $\left(G_{1}\right)$. The values of experimental and numerical maximum incident pressure results on the two targets location are listed in Table (4). The difference between results of field test and proposed model were $30 \%$ for target $\left(\mathrm{G}_{1}\right)$ and $16 \%$ for target $\left(\mathrm{G}_{2}\right)$. It can be noticed that the numerical simulation results showed a good compatibility with the field measurements.

Table (3) Experimental and numerical crater dimensions

\begin{tabular}{|c|c|c|c|}
\hline \multirow{2}{*}{ Test } & \multirow{2}{*}{$\begin{array}{c}\text { TNT } \\
\text { charge } \\
\text { weight } \\
(\mathbf{k g})\end{array}$} & \multicolumn{2}{|c|}{ Crater dimensions } \\
\hline & & Diameter (m) & Depth (m) \\
\hline $\begin{array}{l}\text { Experimental } \\
\text { test results }\end{array}$ & 8 & 2.55 & 2.70 \\
\hline $\begin{array}{c}\text { Numerical model } \\
\text { results }\end{array}$ & 8 & 3 & 2.5 \\
\hline Compatibility \% & --- & $85 \%$ & $93 \%$ \\
\hline
\end{tabular}

Table (4) Experimental and numerical peaks of incident pressure

\begin{tabular}{||c|c||c|c||}
\hline \multirow{2}{*}{ Test } & \multicolumn{1}{|c||}{$\begin{array}{c}\text { TNT } \\
\text { Charge } \\
\text { weight } \\
(\mathbf{k g})\end{array}$} & $\begin{array}{c}\text { Tirectly } \\
\text { under the } \\
\text { ground } \\
\text { surface }\left(\mathbf{G}_{1}\right)\end{array}$ & $\begin{array}{c}\text { at depth, } \text { D= Im } \\
\text { under the ground } \\
\text { surface }\left(\mathbf{G}_{2}\right)\end{array}$ \\
\hline $\begin{array}{c}\text { Experimental test } \\
\text { results }\end{array}$ & 8 & $140 \mathrm{kPa}$ & $168 \mathrm{kPa}$ \\
\hline $\begin{array}{c}\text { Numerical model } \\
\text { results }\end{array}$ & 8 & $98 \mathrm{kPa}$ & $142 \mathrm{kPa}$ \\
\hline Compatibility \% & --- & $70 \%$ & $84 \%$ \\
\hline \hline
\end{tabular}




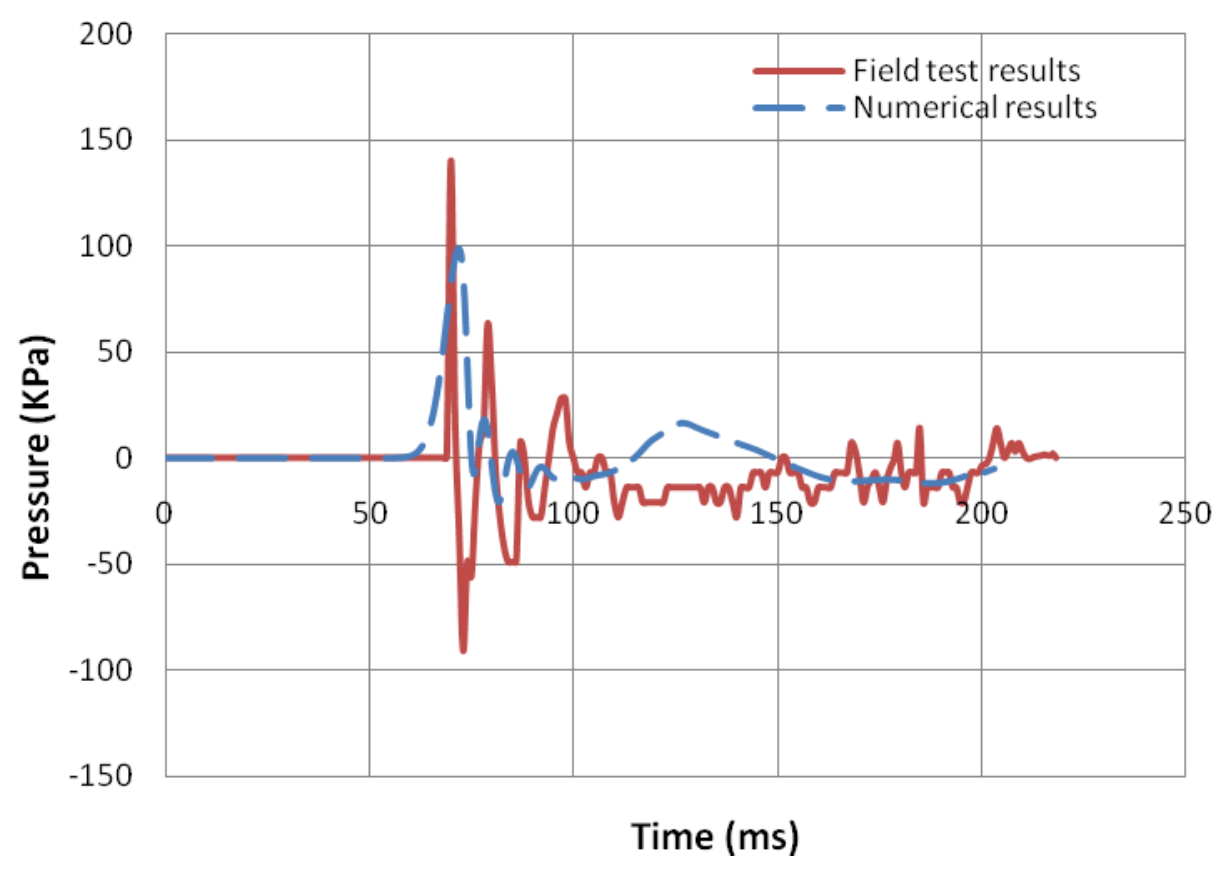

Figure (6): Pressure-Time history for the target $\left(G_{1}\right)$ located directly under the ground surface

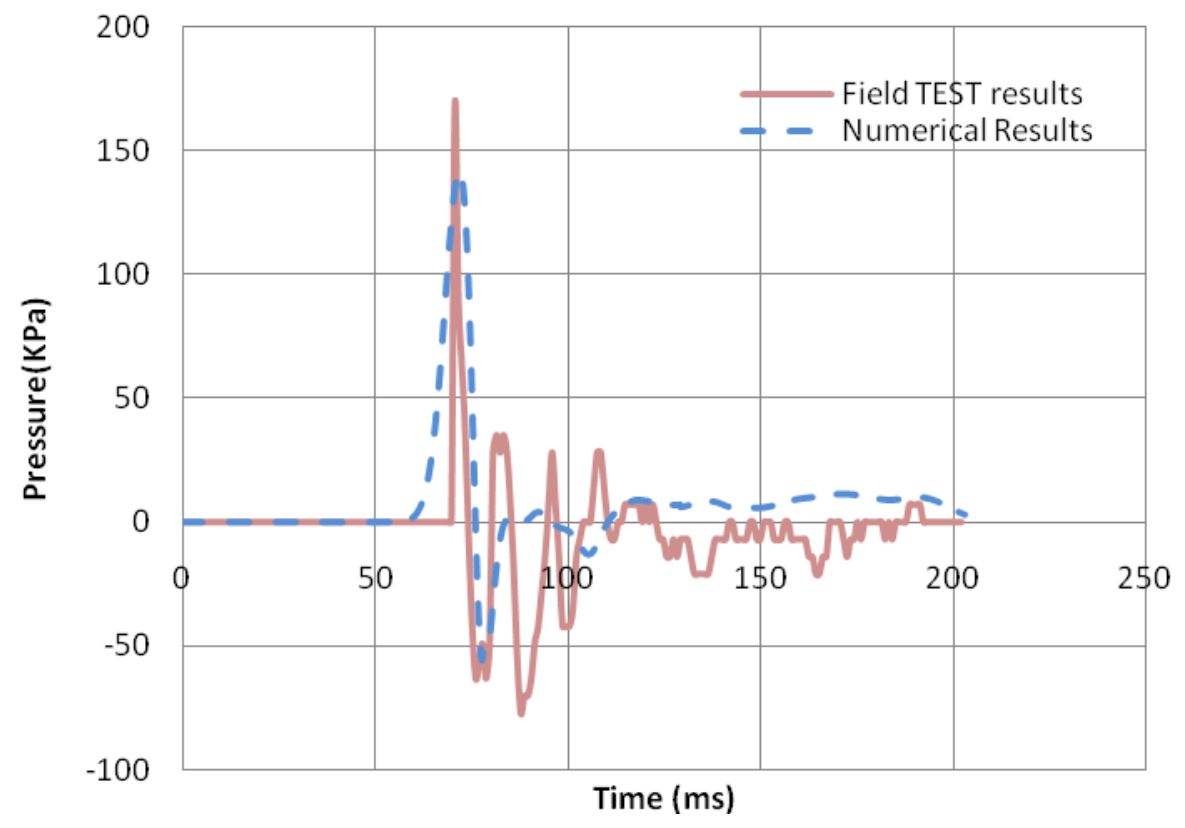

Figure (7): Pressure-Time history for the target $\left(G_{2}\right)$ located at depth $(D=1 \mathrm{~m})$ under the ground surface 


\section{Conclusions}

The proposed finite element model can be used efficiently in characterizing the response of rock mass under the effect of explosion load. The reliability of this model performance is demonstrated by a comparison between finite element models results and experimental ones. It exhibited qualitatively correct behavior compared with the experimental investigation results.

The numerical simulation should be carried out using the equivalent rock mass to achieve the in-situ properties of the rock mass with its reliable geological conditions. The results from the constitutive model RHT that includes strain-rate and damage with a pressure-dependent yield surface shows relatively good agreement with experimental results. The damage contours at the explosion location from the simulation are also consistent with the post-test damage results.

\section{Acknowledgement}

I am deeply grateful to Prof. Dr. Fathalla El-Nahhas, Professor of Geotechnical Engineering, Faculty of Engineering, Ain Shams University, for his inspiration, encouragement and sincere advice which greatly contributed to the research.

\section{References}

[1] H. A. Hasan, A. M. Belal, "Field Testing of Blast-Induced Ground Excitation due to Explosion in Rock Mass" Proceedings of the $8^{\text {th }}$ International Conference on Civil and Architecture Engineering," May 2527, 2010.

[2] Henrych, J., "The Dynamic of Explosion and its Use", Elsevier, Amestrdam, 1979.

[3] S. G. Chen, J. Zhao,"A Study of UDEC Modeling for Blast Wave Propagation in Jointed Rock Mass" Int. J. Rock Mech. and Mining Science., Vol. 35, No. 1, pp.,93-99, 1998.

[4] Wu C, Hao H, Ma G, Zhou YX, "Dynamic Response of Rock Mass with Stochastic Properties Subjected to Explosive Loads". Int. J. Blast Fragment. Vol.3, pp. 137-153, 1999.

[5] Hao H, Wu C, Zhou YX "Numerical Analysis of Blasting Induced Stress Wave in Anisotropic Rock Mass with Continumm Damage Models" Part 1, Equivalent Material Approach, Int. J. Rock Mech. and Rock Eng., Vol.35 (2), pp. 79-49, 2002. 
[6] G. W. Ma, H. Hao, Y. X. Zhou, "Modeling of Wave Propagation Induced by Underground Explosion". Computer and Geotechnics, Vol. 22 (3/4) pp. 283-303, 1998.

[7] C.Wu, H. Hao, "Modeling of Simultaneous Ground Shock and Air Blast Pressure on Nearby Structures from Surface Explosions", Int. Journal of Impact Engineering, Vol. 31, pp.699-717, 2005.

[8] C.Wu, H. Hao, "Numerical Simulation of Structural Response and Damage to Simultaneous Ground Shock and Air Blast Loads", Int. Journal of Impact Engineering, Vol. 34, pp.556-572, 2007.

[9] AUTODYN Explicit Software for Non-linear Dynamics "AUTODYN Electronic Document Library” Century Dynamics Inc., 2005.

[10] C.C. Carranza, Torres, Fairhust, " Application of the ConvergenceConfinement Method of Tunnel Design to Rock Masses That Satisfies Hoek- Brown Failure Criterion ", Tunnelling and Underground Space Technology, Vol. 15, No.2, pp. 187-213, 2000.

[11] E. Hoek, C.C. Carranza, Torres, Bcorkum, "Hoek- Brown Failure Criterion" , Proc.NARMS. TAC. Conference, Totonto, pp. 267-273, 2002.

[12] E. Hoek, M.S. Diederichs “ Emperical estimation of Rock Mass Modulus”, Int. J. Rock Mech. and Mining, Vol. 43, pp. 203-215, 2006.

[13] A. M. Belal, “ Rational Analysis of Tunnels Subjected to Different Explosives Load ", Utilization of Underground Space in Urban areas, 6-7 Nov. 2006, Sharm EL- Sheikh, Egypt.

[14] C.Y. Tham ,"Reinforced Concrete Perforation and Penetration Simulation Using AUTODYN-3D" Finite Elements in Analysis and Design, Vol. 41,pp.1401-1410. (2005).

[15] Z. Wang , H, konietzky, R. Y. Hung, " Elastic-Plastic Hydrodynamic Analysis of Crater Blasting in Steel Fiber Rienforced Concrete " Theoritical and Applied Fracture Mechanics, Vol. 52, pp. 111-116, (2009).

[16] Z L. Wang, Y. C., Li, R. F. Shen, "Numerical Simulation of Tensile Damage and Blast Crater in Brittle Rock due to Underground Explosion ", Int. journal of Rock Mechanics and Mining Science, Vol.44 (5),pp. 730738, (2007). 